\title{
SATURAÇÃO TEÓRICA EM PESQUISAS QUALITATIVAS: CONTRIBUIÇÕES PSICANALÍTICAS
}

\author{
Bruno José Barcellos Fontanella* \\ Ronis Magdaleno Júnior ${ }^{\#}$
}

\begin{abstract}
RESUMO. A técnica de fechamento do número amostral por saturação teórica, comum nas pesquisas qualitativas, em particular na área clínica, dialoga com a teoria e a prática psicanalítica e delas pode se beneficiar. Embora certa imprecisão do número amostral final seja inevitável e inerente aos métodos qualitativos, ela não deveria levar a técnicas e a procedimentos que possam fragilizar ou comprometer a validade empírica e a credibilidade das análises e achados. Este ensaio aborda aspectos das dimensões cognitiva e afetiva, tanto do participante quanto do pesquisador, que se mostram presentes durante a coleta de dados por meio de entrevistas. Para isso são utilizados os conceitos freudianos de transferência e contratransferência e as noções de rêverie e de elementos beta, formuladas por Wilfred Bion. Postula-se que fenômenos dessas ordens ajudam a determinar quanto de dados advindos dos elementos amostrais é suficiente, necessário e possível para o adensamento teórico sobre o objeto estudado.
\end{abstract}

Palavras-chave: Pesquisa qualitativa; coleta de dados; psicanálise.

\section{THEORETICAL SATURATION IN QUALITATIVE RESEARCH: PSYCHOANALYTICAL CONTRIBUTIONS}

\begin{abstract}
The methodological technique of theoretical saturation, commonly used in qualitative researches, particularly about clinic activities, dialogues and can benefit from theory and practice of psychoanalysis. Although some imprecision in the final sample size is inevitable and inherent to qualitative methods, it should not lead to techniques and procedures that can weaken or jeopardize the validity and credibility of both empirical analysis and findings. This essay discusses aspects of cognitive and affective dimensions present during data collection through interviews, in both informants and researchers. For this, the Freudian concepts of transference and countertransference are used, and also the notions of rêverie and beta elements, formulated by Wilfred Bion. It is postulated that these kind of phenomena help determine how much data coming from the sample elements are sufficient, necessary and possible to enhance the theoretical depth of the studied object.
\end{abstract}

Key words: Qualitative research; data collection; psychoanalysis.

\section{SATURACIÓN TEÓRICA EN LAS INVESTIGACIONES CUALITATIVAS: CONTRIBUCIONES PSICOANALÍTICAS}

\begin{abstract}
RESUMEN. La técnica metodológica de saturación teórica, común en la investigación cualitativa, en particular en la clínica, se puede beneficiar de ambas la teoría y práctica del psicoanálisis. A pesar de cierta imprecisión en el tamaño de la muestra final sea inevitable e inherente a los métodos cualitativos, esto no debe dar lugar a técnicas y procedimientos que debiliten o pongan en peligro la validez y la credibilidad del análisis empírico y conclusiones. Este ensayo analiza aspectos de las dimensiones cognitiva y afectiva presentes durante la recolección de datos a través de entrevistas, del participante y del investigador. Para ello, utilizamos los conceptos freudianos de transferencia y contratransferencia y las nociones de rêverie y elementos beta, realizados por Wilfred Bion. Se postula que estos fenómenos ayuden a determinar si la cantidad de datos procedentes de los elementos de la muestra es suficiente, necesario y posible para ahondar sobre el objeto estudiado.
\end{abstract}

Palabras-clave: Investigación cualitativa; recolección de datos; psicoanálisis.

Doutor em Ciências Médicas pela Universidade Estadual de Campinas (Unicamp). Professor Adjunto da Universidade Federal de São Carlos (UFSCar), Brasil.

\# Doutor em Ciências Médicas pela Universidade Estadual de Campinas. Membro Associado da Sociedade Brasileira de Psicanálise de São Paulo (SBPSP). Membro do Laboratório de Pesquisa Clínico-Qualitativa da Unicamp. Brasil. 
Em texto publicado anteriormente com a participação de um de nós (Fontanella, Ricas, Turato, 2008), procurou-se aprofundar o entendimento do processo de amostragem intencional "por saturação teórica", comumente utilizada nas pesquisas empíricas com métodos qualitativos na área dos cuidados aos agravos à saúde ou clínico-qualitativas (Turato, 2010).

Aqui, refletiremos sobre um ângulo desta problemática não suficientemente explorado nesse trabalho anterior. Abordaremos aspectos das dimensões cognitivas e afetivas do pesquisador e dos sujeitos pesquisados, atuantes na relação estabelecida entre ambos por ocasião da coleta de dados. Postula-se que fenômenos dessas dimensões constituam-se em fatores que ajudam a determinar o quanto de dados advindos dos elementos amostrais são suficientes, necessários e possíveis para que ocorra o pretendido adensamento teórico sobre o objeto pesquisado.

$\mathrm{Na}$ construção da argumentação, procuraremos deixar claro que o procedimento metodológico da saturação teórica dialoga e pode se beneficiar de conceitos da teoria psicanalítica e de técnicas e práticas deste campo.

\section{O CONCEITO FÍSICO-QUÍMICO DE SATURAÇÃO E A METÁFORA METODOLÓGICA}

A expressão saturação teórica foi inicialmente utilizada por Glaser e Strauss (1967). É uma metáfora advinda da área físico-química que nessas ciências serve para descrever o comportamento de solutos junto a um meio solvente. Diz-se que uma solução está saturada quando a concentração do soluto é a máxima possível, considerando as condições físico-químicas em que esta solução se encontra.

A transposição desta ideia para a metodologia de pesquisa está baseada na assunção de que quando se coletam dados qualitativos ocorre igualmente uma transferência de materiais (no caso, significações psicoculturais), que passariam de seu meio original (aquele em que se manifestam as particularidades psíquicas e socioculturais de indivíduos ou grupos) para outro meio (aquele do pesquisador). Certamente o pesquisador detém uma matriz teórica que lhe confere uma visão diferente sobre as particularidades de seus sujeitos de pesquisa e está imerso em suas próprias condições psicossocioculturais, das quais também poderá não estar plenamente consciente; entretanto, embora sejam meios diferentes, eles compartilham características.
A metáfora se configura quando se diz que o processo de coleta de dados se saturou teoricamente, ou seja, quando o pesquisador cogita a ocorrência de uma espécie de descarte dos dados mais recentemente coletados, porque não mais contribuem para a elaboração teórica pretendida. $\mathrm{Na}$ prática das pesquisas, é comum que o indicador repetição dos dados seja utilizado para inferir esta redundância e decantamento (Denzin, Lincoln, 1994).

Observe-se que "dizer" ou "cogitar" ter atingido tal ponto tem uma decorrência prática imediata, pois justificará a interrupção de captação de novos membros da amostra.

Consideramos que, se possível, deve-se fazer uma tradução desta constatação para termos técnicos. Trata-se de um processo heurístico sobre dados advindos da empiria cuja objetivação não é feita de forma imediata, precisando o pesquisador explicitar os fatores que identificou como envolvidos na gênese da configuração teórica que realizou. Tal explicitação nos parece importante em razão de as pesquisas qualitativas estarem inseridas nos cânones científicos e, mesmo que seus modelos interpretativos não se filiem de todo à tradição positivista, elas não estão isentas de ser avaliadas quanto ao rigor metodológico empregado em todas as suas fases.

Alguns processos envolvidos na saturação teórica em pesquisas empíricas clínico-qualitativas são comentados a seguir. Expomos os principais argumentos que os definem, as metáforas possíveis, e damos exemplos a respeito das dimensões prática, metodológica, cognitiva e da dinâmica psíquica, e oncológica.

No tocante à dimensão prática, o processo ou os recursos disponíveis (como a escassez de tempo ou a opção por restrição da abrangência da pesquisa) podem dificultar ou impossibilitar o acesso a informantes ou a determinados dados clínicos. A metáfora seria a de um continente (um frasco) com pouca capacidade, comportando pouco solvente e, em decorrência, pouco soluto (em termos absolutos), como, por exemplo, seria a opção de não entrevistar certas pessoas, em princípio, relevantes para a pesquisa, por impossibilidade de acesso a elas.

Quanto à dimensão metodológica, pode acontecer de o objetivo geral do estudo ser restrito, o caráter exploratório dado à investigação ser pequeno, objetivando responder pontualmente a uma ou a poucas questões. Não há incapacidades, insuficiências ou características inerentes aos materiais (solvente/soluto - pesquisador/pesquisados) que os tornem pouco compatíveis, mas uma opção por restringir o que será utilizado de ambos como se dá, 
por exemplo, com a limitação de objetivos em função de ser formulado um problema de pesquisa adaptado ao estágio inicial de formação do pesquisador (p.ex., para iniciação científica).

Quanto à dimensão cognitiva e da dinâmica psíquica, pode ocorrer que elementos advindos dos participantes não sejam apreendidos cognitivamente (por eles próprios e/ou pelo pesquisador), sendo mentalmente descartados, não absorvidos, rejeitados de antemão, e assim os modelos interpretativos existentes não são empregados em razão de limites pessoais do pesquisador. A metáfora seria a de um solvente (pesquisador) que, devido à baixa temperatura (isto é, insuficientes condições cognitivas, culturais ou psicológicas), absorve e comporta pouco soluto, quando, por exemplo, o pesquisador se defronta (ou, talvez melhor, se inquieta) com materiais "pré-verbais" (não simbolizados) de seus entrevistados, ou seus próprios.

A especificidade da dimensão ontológica diz respeito à possibilidade de haver elementos cientificamente irreconhecíveis por falta de um referencial teórico. A comunidade científica não transforma aspectos da realidade empírica em dados, resultando em pontos-cegos ao conhecimento. $\mathrm{O}$ material obtido não é solúvel nos modelos, ferramentas ou paradigmas interpretativos disponíveis nas ciências (isto é, não podem ser diluídos). $\mathrm{O}$ pesquisador explora o campo trabalhando na fronteira do conhecimento; ou os sujeitos pesquisados pertencem a um grupo cultural desconhecido, ou vivenciam uma problemática ainda inexplorada.

Nosso objetivo aqui será teorizar o terceiro item listado (influência das questões cognitivas e psicodinâmicas da dupla pesquisador/pesquisado no processo de saturação), que guarda uma especificidade grande quando o empreendimento lida com objetos relacionados à clínica dos agravos físicos ou mentais à saúde, tais como observados em contextos de cuidado como ambulatórios, hospitais e consultórios dos variados tipos de profissionais de saúde (médicos, enfermeiros, psicólogos, fisioterapeutas, terapeutas ocupacionais etc.).

Embora utilizemos conceitos da psicanálise, pretendemos que nossas considerações se apliquem, de modo inclusive preferencial, às investigações clínico-qualitativas que envolvem settings não psicanalíticos de cuidado.

\section{QUESTÕES COGNITIVAS E DAS DINÂMICAS PSICOCULTURAIS ENTRE PESQUISADOR E PARTICIPANTES}

No papel de pesquisador qualitativo, um clínico, de qualquer área do cuidado à saúde, defronta-se com determinados elementos (possíveis dados), advindos dos participantes, que não serão apreendidos. Embora a priori estejam disponíveis no campo de pesquisa, serão descartados ou ignorados, pela impossibilidade (em termos psicológicos ou culturais) de serem avaliados e percebidos como dados.

Este fenômeno pode ser gerado por variados fatores, mas culminam todos por tornar o pesquisador incapaz de ter esses elementos disponíveis à sua consciência, no sentido de gerar um discurso lógico, compreensível e passível de veiculação científica. $\mathrm{O}$ efeito prático produzido pode ser a convicção de que o trabalho de campo não acrescenta nada de novo. $\mathrm{Na}$ realidade, tratar-se-ia de uma impossibilidade de o pesquisador articular e compreender os elementos disponíveis, resultando numa avaliação errônea do timing para o fechamento amostral.

Uma matriz teórica insuficiente do pesquisador pode explicar parte dessa indisponibilidade, mas postula-se que outros fatores de seu domínio, de ordem que se pode dizer subjetiva ou pessoal, atuem nesta dificuldade, impedindo-o de perceber (escutar) e avaliar (analisar) certos conteúdos, em razão de não conseguir articular uma compreensão lógica no rapport com determinado entrevistado. $\mathrm{O}$ mesmo conteúdo, advindo do mesmo entrevistado, poderia ser apreendido por outro pesquisador menos limitado por seus próprios conflitos geradores de angústia. Assim não se trata, aqui, de questões ou dificuldades ontológicas gerais, pois há ferramentas teóricas interpretativas suficientes no campo de conhecimento do pesquisador, mas sim, da impossibilidade de um pesquisador em específico apreender elementos na forma de dados.

Este fator constituir-se-ia em um grande empecilho no caso de um estudo de caso único, mas quando se lida com uma amostra que permite múltiplas observações, ele é minimizado pelo fato de outras pessoas também fornecerem informações utilizando outras formas de comunicação. Algo que não foi apreendido na interação com um participante poderá sê-lo com outro, salvo, como veremos adiante, se questões relacionadas a áreas cegas do pesquisador estiverem atuantes.

Fatores do domínio dos sujeitos pesquisados também podem gerar dificuldades de compreensão, sobretudo quando estes têm dificuldade ou incapacidade para elaborar ou transmitir verbalmente determinados elementos de maneira inteligível para o raciocínio lógico do pesquisador.

Excetuando-se a questão de uma matriz teórica não dominada, nos outros casos mencionados o que se cogita é haver processos não conscientes 
influenciando a coleta de dados, os quais, assim, ficam indisponíveis para o pesquisador, para o pesquisado ou para ambos.

Destarte, o pressuposto com o qual trabalhamos é que nas pesquisas qualitativas na área clínica as angústias da dupla pesquisador-entrevistado atuam de modo muitas vezes decisivo no decantamento (descarte) de possíveis dados que, em tese, seriam úteis aos propósitos da investigação. Procuraremos, a seguir, dissertar sobre uma menção feita apenas en passant no referido texto anterior (Fontanella, Ricas, Turato, 2008), quanto à utilidade do conceito desenvolvido por Bion de elementos beta para compreender esta situação. Para aprofundar a compreensão do processo, discorreremos também sobre as limitações impostas ao pesquisador por seus mecanismos de defesa frente à angústia.

\section{COMPREENDENDO O PROCESSO DE SATURAÇÃO TEÓRICA A PARTIR DE CONTRIBUIÇÕES PSICANALÍTICAS}

O fechamento amostral por saturação teórica leva à suspensão da inclusão de participantes quando os dados passam a apresentar, na avaliação do pesquisador, certa redundância ou repetição (Glaser, Strauss, 1967; Denzin, Lincoln, 1994). Nessa definição, encontramos duas referências à participação direta da subjetividade do pesquisador: as questões da "avaliação do pesquisador" e da "repetição" como balizadores do processo.

O reconhecimento da participação ativa da subjetividade do pesquisador nas técnicas e procedimentos qualitativos talvez permaneça controverso aos olhos dos quantitativistas, mas, para os qualitativistas essa participação é importante para o próprio reconhecimento de sua cientificidade. A inserção radical do pesquisador no campo (interagindo com ele e, desta forma, também gerando dados) é parte integrante do método. $\mathrm{O}$ pesquisador estaria "envolvido (...) com o seu objeto de estudo, tendo que misturar-se com ele, identificar-se" (Turato, 2010, p. 25). Deste modo, sugere-se uma inserção visceral do pesquisador em seu campo de trabalho e se chega mesmo a propor um mecanismo de identificação com seu objeto de estudo, como parte do processo de procura da verdade. Bleger explicitou essa ideia quando considerou que

O instrumento de trabalho do entrevistador é ele mesmo, sua própria personalidade, que participa inevitavelmente da relação interpessoal, com o agravante de que o objeto que deve estudar é outro ser humano, de tal maneira que, ao examinar a vida dos demais, se acha diretamente implicada a revisão e o exame de sua própria vida, de sua personalidade, conflitos e frustrações. (Bleger, 1989, p.26).

Tudo isso remete a uma particularidade dos métodos qualitativos: as variáveis ligadas à subjetividade do pesquisador não são entendidas imediatamente como vieses anticientíficos, mas podem constituir-se em elementos significativos para a decifração do material que os entrevistados oferecem. Parece-nos ser esse o ponto de maior tensão epistemológica desses métodos, já que a subjetividade do pesquisador é, ao mesmo tempo, fonte de criatividade e de possíveis vieses pessoais, no caso de se exacerbar numa postura tendenciosa subjetivista.

Neste sentido, as contribuições das teorias psicanalíticas ajudam a instrumentalizar os pesquisadores que se debruçam sobre o sofrimento humano para a escuta e compreensão dos sujeitos investigados, visando alcançar o sentido não apenas de suas falas manifestas, mas também os significados não conscientes, aqueles que só podem ser inferidos a partir desta "escuta" peculiar. São, basicamente, os fenômenos ditos transferenciais e contratransferenciais, descritos por Freud, que ampliaram a compreensão da comunicação humana e que, ao mesmo tempo, passaram a exigir dos pesquisadores cuidados e conhecimentos maiores sobre o funcionamento mental, sobretudo da dinâmica das relações interpessoais.

Deste modo, um pesquisador aberto a um movimento introspectivo, sensível e apto a lidar com a transferência e com a contratransferência, terá ao seu dispor um potencial repertório de sentidos para fenômenos de outro modo inacessíveis; já um pesquisador não atento ou despreparado para lidar com tais fenômenos terá suas capacidades compreensivas reduzidas, em vista do conjunto de modelos teórico-interpretativos hoje existentes.

Dito de outra forma, é relevante para o processo de saturação teórica considerar o alcance do horizonte interpretativo que o pesquisador tem em relação aos dados, sobretudo no que se refere aos seus próprios pontos de angústia (Freud, 1926/1976). Estes criam pontos cegos, nos quais a percepção fica limitada e enviesada pelos próprios atributos do pesquisador. Como é ele próprio quem avalia o ponto a partir do qual novas informações "não acrescentam" às suas formulações, é desejável que tenha ao seu dispor um amplo leque de recursos mentais para transformar em 
dados a angústia, o sofrimento, as sobrecargas e as descargas afetivas do entrevistado.

Um pesquisador com pouca experiência clínica ou com poucos recursos pessoais para lidar com a angústia pode ser instado a não ver nada de novo no material de seus entrevistados quando toquem em questões conflitivas suas.

Como advertiu Freud (1914/1969), a repetição acorre ao psiquismo quando a resistência chega ao ponto de irromper uma angústia não tolerada pelo sujeito, que passa então a lançar mão de mecanismos de defesa. Nesse sentido, a "repetição" identificada pelo pesquisador pode expressar nada mais do que sua própria impossibilidade de ir adiante na compreensão de fenômenos vivenciados pelos entrevistados, e sendo assim, o pesquisador é que estaria preso a um ciclo de repetições, e não os seus entrevistados. Nesses casos, as defesas do pesquisador é que estariam em ação, não suas funções cognitivas, as quais são fundamentais para desenvolver um sistema dedutivo científico (Bion, 1973).

Um conceito-chave para compreender esse fenômeno parece-nos ser o de tolerância (Bion, 1973). Durante todo o processo de coleta de dados o pesquisador clínico é submetido a situações que "testam" sua capacidade de tolerar o não saber, a angústia e a dor, tanto dos sujeitos que vivem processos patológicos como, contratransferencialmente, a própria angústia por identificação com o sofrer do outro. Assim, deslocando a teoria de Bion do campo originalmente proposto por ele, que é a mente e seu funcionamento primitivo, para o setting da pesquisa, concebemos que o pesquisador "tolerante" tem a seu dispor maiores possibilidades de observar conjunções constantes (Bion, 1973) entre fenômenos, nomeá-las e usá-las para investigar seus significados. $\mathrm{Na}$ construção do saber científico qualitativo, esse seria um procedimento fundante da validade dos achados e do conhecimento.

Por outro lado, o pesquisador não tolerante à angústia tem seu campo perceptivo e compreensivo reduzido, ficando obrigado a lançar mão de mecanismos de defesa, o que terá como possível consequência o fechamento amostral prematuro. As pré-concepções do pesquisador (seu arcabouço teórico, suas vivências clínicas pessoais, sua sensibilidade à comunicação do outro e sua capacidade de conhecer a si próprio) ficam impedidas em seu potencial heurístico, transformando-se em subjetivismo anticientífico (Bion, 1973).

Num esforço de aproximação teórica, relacionamos o conceito de saturação desenvolvido por Bion com seu uso em metodologia qualitativa. Para ele, a saturação está ligada a uma conjunção constante, ou seja, aplica-se quando a "coisa" recebe representações que a "saturam" e a cristalizam, anulando seu potencial criativo de expansão simbólica. Partindo desse modelo, a saturação teórica seria, então, o momento no qual se aplica a uma vivência observada o máximo de significados possível, balizando um saber científico válido. No sentido proposto por Bion, "saturação" tem uma conotação algo negativa, contrariamente a seu uso em ciência acadêmica processual, pois, neste caso, aponta para um saber estabelecido, para uma conclusão, ao mesmo tempo fornecendo respostas às inquietações do pesquisador e sendo a porta de entrada para novas insaturações e perguntas.

Podemos pensar, então, em dois níveis de saturação. O primeiro decorreria da impossibilidade de o pesquisador expandir os sentidos ligados a certos fenômenos, sendo uma resposta à intolerância e à frustração e conduzindo a um fechamento amostral precoce - talvez melhor descrito metaforicamente como cristalização. No segundo nível, a saturação contribui efetivamente para finalizar a coleta de dados, e dependeria da capacidade do pesquisador para tolerar angústia e frustração até o momento em que os dados se constituíssem em concepções e conceitos articuladores de significados. Tratar-se-ia de uma mescla de material vindo do entrevistado e de elaborações do pesquisador decorrentes de sua virtuosidade clínica, abrindo espaço para hipóteses outras que não aquelas atadas a uma clínica monocórdica, ou seja, para uma expansão da clínica.

\section{UTILIZANDO OS CONCEITOS BIONIANOS DE ELEMENTOS $\beta$ E DE R̂EVERIE EM PESQUISA QUALITATIVA}

A reconstrução científica da realidade - ou a busca da validade, ou da verdade - deve prescindir de maneiras uniformes de abordar objetos e problemas variados, devendo as preferências metodológicas ou epistemológicas importar menos do que a "realidade empírica" com que se defronta (Pires, 2008).

A psicanálise lida com "realidades nãosensoriais" (Bion, 1973, p.20) constitutivas do humano, em qualquer setting em que se insira. Neste sentido, "as realizações, com as quais o psicanalista lida, não podem ser vistas nem tocadas; a ansiedade não tem forma, cor, cheiro ou som" (Bion, p.8). Ao colocar-se diante de seu entrevistado, o pesquisador clínico-qualitativo irá 
receber dele um discurso lógico e racional e também um lote de "realidades não sensoriais". Para reconstruí-las, Bion elaborou formulações teóricas, algumas delas úteis à discussão que aqui propomos.

Ele postulou a existência de elementos psíquicos não elaborados, aos quais denominou elementos $\beta$. Estariam destinados, na dinâmica psíquica, à descarga, e não à elaboração, por não serem simbolizados e não fazerem parte do pensamento (Bion, 1973). Transpondo esse fenômeno para o campo da pesquisa qualitativa, entendemos que, do material disponibilizado pelo entrevistado, uma parte se destinaria, de antemão, somente ao descarte, e não à elaboração teórica (não transformação em dados), necessitando, para se tornarem úteis à construção do saber, ser transformados e nomeados pelo que recebe tais elementos, o pesquisador.

Estes elementos fariam parte da estrutura mental do entrevistado e impõem um ruído na comunicação com o pesquisador, impossibilitando que suas funções cognitivas atuem com clareza e criatividade. Nessas condições, faltam elementos para raciocinar e fazer inferências válidas. Tais elementos $\beta$, - utilizando-se a metáfora digestiva proposta por Bion -, não teriam sido metabolizados psiquicamente pelo entrevistado, chegando ao entrevistador como material bruto e não se prestando, assim, à compreensão e ao desenvolvimento do pensamento. Estes elementos não seriam situáveis no "espaço mental" do sujeito, ficando inacessíveis à sua hermenêutica e, por conseguinte, à hermenêutica do pesquisador, situando-se, ontologicamente, antes dos símbolos ou da capacidade simbólica. Nesse contexto, o discurso do entrevistado cria áreas de sombra ou ruído que podem provocar, defensivamente, afastamento do clínico investigador. Tal afastamento por intolerância ao não saber pode se expressar como uma dificuldade de escuta ou - o que é o foco de nosso trabalho - como uma interrupção prematura (ou um adiamento infrutífero do fim) da coleta de dados. Pode mesmo comprometer a fundamentação da pesquisa - caso os elementos descartados sejam essenciais aos seus objetivos - ou superficializar os achados, que tenderiam ao lugar comum, ou mesmo a levar a juízos morais ou ideológicos. É nesse ponto que a prática de supervisão do material obtido, com a ajuda dos pares ou de um supervisor em específico habilitado, torna-se desejável e até indispensável.
Bion desenvolve o conceito de rêverie como uma função necessária para elaborar internamente poderíamos dizer, compreender - os elementos $\beta$ recebidos e devolvê-los ao emissor de uma forma utilizável como elementos do pensar. Para Bion, esses elementos servem à comunicação, porém em um nível altamente primitivo, necessitando ser como que metabolizados por aquele que os recebe, atividade que depende da capacidade de rêverie (Bion, 1991; Bion 2004a).

Rêverie pode ser definido como um estado particular de consciência receptiva e a capacidade de se manter nesse estado (Parson, 2007). Seria uma atitude receptiva que permitiria acolher a transmissão de conteúdos primitivos do outro, possibilitando articulações, relações e vínculos na matriz de significações, com a criação de novos significados. Para Bion (2004b), a função rêverie materna é receptora da sensação de "si mesmo" do bebê e é conceito presente em sua teoria do pensamento, da capacidade de tolerar a frustração e do processo de conhecimento (Bion, 1962, 1967).

Questionamo-nos sobre a utilidade de desenvolver o equivalente da função de rêverie no pesquisador, o que the possibilitaria receber, metabolizar e transformar continuamente o que chega de seus entrevistados em "imagens visuais intuitivas" (Ferro, 2008) propiciadoras da expansão do conhecimento. Deste modo ele expandiria também sua capacidade de "devolver" de forma elaborada para seus leitores uma compreensão coerente e válida do que foi apreendido em campo, sobretudo daqueles elementos mais sutis da comunicação do entrevistado.

\section{DESENVOLVENDO A CAPACIDADE DE RÊEERIE DO PESQUISADOR}

A capacidade de compreender o que o outro comunica é constitutiva do humano, mas seu alcance varia entre os indivíduos. Partindo dos modos como a formação dos clínicos e de como a rotina acadêmica dos grupos de pesquisa costuma se dar, pensamos em possibilidades de inserir nesses itinerários institucionais o desenvolvimento de habilidades para melhor apreensão dos conteúdos não conscientes da comunicação dos entrevistados. Parece-nos fundamental a aquisição de instrumentos que lhe possibilitem reconhecer tais elementos pré-verbais, primitivos e não elaborados da comunicação do entrevistado e seus efeitos. Como essa capacidade corresponde a uma função humana natural, caberia às 
instituições formadoras favorecer seu desenvolvimento.

É útil usar como exemplo a formação psicanalítica, cujo fundamento principal é aperfeiçoar a escuta clínica, desenvolvendo habilidades para compreender os sentidos que as experiências de vida têm para o paciente e como tais sentidos chegam ao receptor, em sua intimidade. Isto possibilita que ele infira sentidos subjacentes àquelas experiências que por vezes são inconscientes para o próprio emissor.

Sistematizando uma proposta para este desenvolvimento, comentaremos algumas táticas, discriminadas e descritas a seguir.

a. Aquisição de experiência clínica envolvendo o objeto de pesquisa

As pesquisas clínico-qualitativas abordam um campo específico de fenômenos aos quais se tem acesso a partir do desenvolvimento de uma klinike techne correspondente ao objeto investigado. Não se trata apenas de garantir certo grau de experiência clínica, mas de um contato frequente e engajado do clínico com seus pacientes capaz de possibilitar o desenvolvimento de uma função equivalente à rêverie. Isto demanda investimento pessoal e tempo, o tempo habitual de formação de uma experiência clínica que torne o profissional um virtuose em suas funções, capaz de lidar adequadamente com a demanda emocional de seus pacientes. Em outras palavras, o profissional deve estar apto inicialmente a ver seus pacientes "de fora" (a partir da perspectiva das ciências da saúde - ou sensorialmente, como referiu Bion) para depois aventurar-se a compartilhar com seus pacientes a visão que eles próprios têm (ou ver intuitivamente), habilitando-se a apreender sentidos e a formular criativamente elaborações teóricas sobre as vivências dos sujeitos da pesquisa.

b. Expansão da matriz teórica à disposição do pesquisador

A expansão do conhecimento teórico sobre certo campo de conhecimento é fundamental para que o pesquisador possa produzir a partir do que já existe. Sua falta impõe a repetição de análises já conhecidas e a falta de pontos de partida já estabelecidos para balizar novos conhecimentos. $\mathrm{O}$ pesquisador deve conhecer suficientemente os modelos de funcionamento mental, sobretudo no que se refere à comunicação de elementos não observáveis diretamente pelo sensório ou pela razão e de suas inter-relações com o outro.

c. Revisão supervisionada do corpus de entrevistas

Seguindo a linha aqui proposta, o corpus seria composto por dois tipos de material: aquele já evidente e aquele que necessita da capacidade de rêverie do pesquisador, da discussão com um supervisor capacitado e com os pares.

$\mathrm{O}$ material evidente prestar-se-ia melhor à saturação teórica como proposta na literatura metodológica, pois os elementos de repetição e a avaliação do pesquisador estão mais facilmente disponíveis, demandando apenas uma observação atenta, paciente e interessada, além do domínio do campo teórico correspondente.

O material que demanda uma capacidade de rêverie depende de especificidades do pesquisador e de seu grupo de pesquisa. As pesquisas devem ser desenvolvidas, mas isto demanda tempo e dedicação adicionais. Tratar-se-ia de um percurso que depende da capacidade do pesquisador de envolver-se com áreas insaturadas do conhecimento e de sua tolerância à angústia diante do não conhecido.

Teoricamente, o ponto de saturação para um pesquisador iniciante e com pouco domínio sobre as questões psicodinâmicas sutis seria anterior ao ideal, pois tenderia a captar apenas os elementos sensoriais e a lançar mão mais facilmente de mecanismos de defesa diante do ruído na comunicação imposto pela angústia e pelo sofrimento. Haveria, pois, uma demanda natural de um aprendizado específico desse aluno visando ao timing correto da saturação.

d. Orientação por pesquisador experiente com conhecimentos teóricos e práticos de dinâmica psicológica interpessoal

A presença de pesquisadores seniores, familiarizados com a dinâmica psicológica, os quais Bion qualifica de "experientes em realidades não sensoriais" (Bion, 1973, p.20), parece-nos fundamental para a constituição de grupos de pesquisa qualitativa sobre objetos clínicos, visto que as subjetividades do pesquisador e as dos pesquisados têm lugar de destaque. Não considerá-las implica a possibilidade de assumir um grave viés metodológico, pois a subjetividade não deixa de existir, pelo contrário, expressa-se de modo não elaborado, podendo resultar em subjetivismo e senso comum, quando não em ratificações ideológicas.

\section{CONCLUSÃO}

É chamativo que o texto de Bion (1973) aqui citado frequentemente (publicado originalmente em 1970) seja praticamente coetâneo ao de Glaser e Strauss (1967). Ambos utilizaram, em seus 
respectivos textos, o termo saturação e, embora tenham feito formulações em campos diferentes, detectamos analogias nos significados que deram à expressão. Ambas as obras também se fundamentaram fortemente em suas respectivas empirias.

Essas coincidências nos foram intelectualmente estimulantes, pois o problema que nos propusemos abordar tem também um caráter voltado à empiria das pesquisas qualitativas. Embora de formulação simples, a questão "quando interromper a captação de novos participantes em uma pesquisa qualitativa?" é essencial a qualquer empreendimento investigativo qualitativo.

Há certamente um grau de imprecisão ou aproximação quanto a um número ideal de componentes para atingir o ponto de saturação teórica. No mínimo, como assinalado antes (Fontanella, Ricas, Turato, 2008), está em jogo o fato de que sua constatação depende diretamente de observações realizadas necessariamente posteriormente à saturação.

Tal imprecisão, que se assume de antemão como inevitável e inerente ao método, não deveria levar a técnicas ou procedimentos que resultem numa fragilidade argumentativa e, no extremo, num engano metodológico comprometedor da validade empírica e da credibilidade de análises e achados.

Um procedimento simples para tentar mitigar esses efeitos seria deixar o corpus das entrevistas disponível a outros leitores/analistas de dados, contanto que seja previsto no protocolo aprovado pelo competente comitê de ética em pesquisa. Em tese, eles poderiam perceber indícios da ocorrência de certos fenômenos da dupla pesquisadorpesquisados e considerar acréscimos teóricos e outros pontos mais adequados de saturação.

Cabe ainda comentar, nesta conclusão, que discutimos apenas questões do domínio da subjetividade dos envolvidos numa pesquisa qualitativa. Elas são paralelas a questões culturais que podem ser igualmente responsáveis por descartes de possíveis dados. Posições excessivamente etnocêntricas dos pesquisadores (decorrentes de pouca familiaridade com o objeto, barreiras de linguagem, insuficiente aculturação a determinado setting clínico etc.) podem impossibilitá-los de compreender alguns valores culturais ou modos de apreensão de elementos do cotidiano dos participantes. A familiarização com o campo de estudo, tanto a partir do conhecimento teórico como da aculturação ao setting clínico, pode minimizar este tipo de dificuldade.
Em suma, parece-nos fundamental que o pesquisador tenha, desenvolvida em si, a capacidade natural de rêverie e de tolerar o não saber para que possa apreender e inferir de modo consistente os elementos mais primitivos da comunicação do entrevistado, sem cair nas "armadilhas" construídas pelos seus mecanismos de defesa, que poderiam levar a posicionamentos ideológicos (que chamaríamos de "saturação ideológica") ou à superficialização da compreensão dos dados ("saturação precoce"), ou ainda à impossibilidade de atingir a saturação, sendo o fechamento amostral feito aleatoriamente ("saturação circunstancial").

\section{REFERÊNCIAS}

Bion, W. R. (1962). Learning from experience. London: Karnac Books.

Bion, W. R. (1973). Atenção e interpretação: uma aproximação científica à compreensão interna na psicanálise e nos grupos. Rio de Janeiro: Imago (Original publicado em 1970).

Bion, W. R. (1991). O aprender com a experiência. Rio de Janeiro: Imago. (Original publicado em 1962).

Bion, W. R. (1994). Uma teoria sobre o pensar. In W. R., Bion. Estudos Psicanalíticos revisados. Rio de Janeiro: Imago. pp. 127138. (Original publicado em 1967).

Bion, W. R. (2004a). Elementos de psicanálise. (2a ed.). Rio de Janeiro: Imago (Original publicado em 1963).

Bion, W.R. (2004b). Transformações. Do aprendizado ao crescimento. Rio de Janeiro: Imago (Original publicado em 1965).

Bleger, J. (1989). Temas de psicologia: entrevista e grupos. (4a ed.). São Paulo: Martins Fontes.

Denzin, N. K., Lincoln, Y. S. (1994). Handbook of qualitative research. Thousand Oaks: Sage.

Ferro, A. (2008). "Tecnica e criatividade”: o trabalho analítico. Rio de Janeiro: Imago.

Fontanella, B. J. B., Ricas, J., Turato, E. R. (2008) Amostragem por saturação em pesquisas qualitativas em saúde: contribuições teóricas. Cadernos de Saúde Pública. 24(1), 17-27.

Freud, S. (1969). Recordar, repetir e elaborar (novas recomendações sobre a técnica da psicanálise II). (J. Salomão, Trad.). Edição standard brasileira das obras psicológicas completas de Sigmund Freud (Vol.XII, pp. 191-203). Rio de Janeiro: Imago. (Original publicado em 1914).

Freud, S. (1976). Inibições, sintomas e ansiedade. (J. Salomão, Trad.). Edição standard brasileira das obras psicológicas completas de Sigmund Freud (Vol. XX, pp. 95-207) Rio de Janeiro: Imago. (Original publicado em 1926).

Glaser, G., Strauss, A. (1967) The discovery of grounded theory: strategies for qualitative research. New York: Aldine de Gruyter.

Parsons, M. (2007). Sobre a rêverie. Rêverie: Revista de Psicanálise, 1(1), 73-76. 
Pires, A. P. (2008). Amostragem e pesquisa qualitativa: ensaio teórico e metodológico. In Vários Autores. A pesquisa qualitativa: enfoques epistemológicos e metodológicos. Petrópolis: Vozes.

Turato, E. R. (2010) Tratado da metodologia da pesquisa clínicoqualitativa: construção teórico-epistemológica, discussão comparada e aplicação nas áreas de saúde e humanas. (4a ed.). Petrópolis: Vozes.

Recebido em 17/08/2011

Aceito em 01/03/2012
Endereço para correspondência: Bruno José Barcellos Fontanella. Departamento de Medicina, Centro de Ciências Biológicas e da Saúde, Universidade Federal de São Carlos (UFSCar). Rodovia Washington Luís, km235. SP-310, CEP 13.565-905, São Carlos-SP, Brasil. E-mail: bruno.fontanella@gmail.com. 